\title{
Leadership of Organization Administrators under the Era of Technological Change
}

\author{
Bunchira Phuchanajita ${ }^{1}$, Aphiwat Jata ${ }^{2}$, Duangjai Pintamul ${ }^{3}$, Lampong Klomkul ${ }^{4}$ \\ ${ }^{1}$ Program Faculty of Political Sciences, Pathumthani University,Thailand, \\ ${ }^{2}$ Nakhon Ratchasima Sangha College, Mahachulalongkornrajavidyadlaya University, Thailand \\ ${ }^{3,4}$ Mahachulalongkornrajavidyalaya University,Thailand \\ ${ }^{1}$ m.chanajita@gmail.com, ${ }^{2}$ wat111phuwiang@gmail.com, ${ }^{3}$ dpintamul@gmail.com, ${ }^{4}$ research.mcu@gmail.com
}

\begin{abstract}
"Leadership of Organization Administrators under the Era of Technological Change" is an academic article aims to study leadership of organization administrators under the era of technological change. Being able to lead an organization, administrators must view change as a challenge or opportunity and know how to make an effective change from inside and outside organizations. They must be able to build consciousness to organizations, as leaders of change. Meanwhile, they have to enable organizations view change as a new opportunity to ensure organization management gain maximum benefits and organizations can be developed in a secure and sustainable manner.
\end{abstract}

Keywords

Leadership, organization administrator, the era of technological change

Article Received: 10 August 2020, Revised: 25 October 2020, Accepted: 18 November 2020

\section{Introduction}

Today, the world is full of rapid change in every aspect, having an impact on all organizations. Emphasis is placed on proactive operations and smart management strategies. Relying on cable leaders only may not be enough to achieve effective management for modern organizations or organizations in the 21 st century as competition is quite high. Therefore, leaders have to exchange knowledge and skills with followers or team members to ensure the team has development, self-leadership, and self-management much enough to collaborate with leaders to lead organizations and solve complex problems in an efficient manner. The important thing to develop efficient collaborative working is developing followers to become self-leader, challenging leaders or administrators in this era of change. Organization leaders play an important role in driving the process to be mobilized efficiently. Leadership characteristics and behaviors have an effect on behaviors of employees in organizations and if any organization needs to change, leadership gives a high impact on organizational success and leads the organization to a better situation.

Transformational leadership comprises intelligence, emotional maturity, vision, ability to motivate others, ability to motivate employees to have organizational commitment and determination to reach organizational goals including knowledge about social situations, economic, political and environment situations, encouraging organizations to be able to regularly adjust themselves to changing situations. As for the goals of management, in addition to benefits and business growth, organizations have to consider progress like stability and sustainability. [1] According to Bass [2], transformational leadership is paradigm shift that leads to leadership with vision. Emphasis is placed on decentralization or assigning authority. Leaders possess morality and encourage followers to have a sense of leadership.
In the context of Thailand, which has encountered economic, social, and political changes, most scholars view that organizational change components are personnel or people, attitudes and abilities of personnel, organizational structure, chain of command, and organizational communication including technology, culture, and value. With regards to transformational leadership, scholars propose that situational leadership model is suitable for changes. Most scholars give importance to leadership potential in terms of leading a guideline for decisionmaking, problem-solving skills, promoting and supporting followers. Besides, most scholars said that leaders should be able to choose appropriate media through various channels, use plain and simple language, and pay attention to listening. Importance and relationship of organizational changes have an impact on the roles of leaders. Organizational leaders need to pay attention to and study such changes as a guideline for organizational management so as to increase competitive advantage to achieve maximum efficiency and effectiveness and develop organizations in a stable and sustainable manner.

\section{Leadership}

\section{Meaning of leadership}

Leadership is the ability of an individual who can encourage changes in another persons or a group of people by motivating them to use their own abilities to act towards such changes[3] Full range leadership model comprises transformational leadership, transactional leadership, freerein leadership or poor leadership behavior.

Influential leaders can motivate other people to act towards achieving an organizational common goal. The process of leadership is related to the use of power and duty to help achieve team goals. Motivating organizational members to work and achieve the set goals has an influence 
on group mechanism and group culture. Leadership relies on motivating people[4]. It is a process that a person can persuade subordinates to behave in a certain way toward an intended guideline. Thus, leadership is both a process and qualification of leaders.

The process of leadership is the use of influence without forcing to direct and coordinate tasks of group members to achieve the team goals[5].

\section{Transformational leadership}

Transformational leadership means behaviors that a leader shows the management ability and a process of management that a leader influences followers: Interactions between leaders and followers bring changes to both parties. Namely, good transformational leaders should be aware of followers' needs and encourage them to have consciousness, elevate followers' needs to reach a favorable level. Transformational leaders change beliefs and attitudes of followers, inspire them and make them to be aware of mission and vision. Importance is given to benefits of others and emphasis is placed on achieving a common goal. [6] The process that leaders have an influence on coworkers or followers shall be implemented through 4 elements (The four I's of leadership), according to the theory of Bass \& Avolio[7] as follow:

1. Idealized influence refers to the way leaders behave themselves to be highly respected and encourage followers to take pride in when working together. Characteristics of leaders are having broad vision that can be transmitted to followers. They are able to control their emotions in crisis situations. They behave themselves for the benefits of others, they are smart, determined, and have self-confidence, and adhere to ideology.

2. Inspirational motivation means the way that leaders motivate followers to have inspiration. They give meaning and challenge in work, making followers active and enthusiastic. They build positive attitudes and possess positive thinking. Leaders will show their devotion to goals and vision. Leaders may build inspiration through individuals and intellectual stimulation, helping followers be able to handle their own obstacles.

3. Intellectual stimulation means the way that leaders stimulate followers to realize ongoing problems in organizations. By doing this, followers have creativity and search for a new method to solve such problems. Leaders stimulate followers to feel that the ongoing problems are challenging their abilities and followers are encouraged to create and propose new things and can solve problems by themselves.

4. Individualized consideration means leaders shall promote and develop potential of followers and coworkers to a higher level. Opportunities to learn new things are given. Individual differences are understood and accepted. Followers are given opportunities to exercise their abilities at full capacity.

\section{Leaders and organizational change}

Organizational change means a process that makes an organization change from current conditions to desirable conditions that comprehensively cover various dimensions.
It shall increase work ability to organizations and develop organizations in the required direction, and respond to the needs of people in organizations, aiming to achieve organizational goals at the end. There are 2 major characteristics of organizational change[8] as

1. Internal organizational change refers to changes occur within organizations such as creating new vision, change of positions, change of supervisors, business expansion, change or modification of policies, adopting technology in workplace. Internal organizational change can be controlled.

2. External organizational change refers to changes occur from environment surrounding organizations such as competitors' strategic changes, laws, policies from the government sector, technological advancement, currency fluctuation, fuel price adjustment, etc. External organizational change cannot be controlled.

Organizational change to respond to changes in internal and external organization environment is not easy and several times it may not be successful. Executives may thing that changes can be made by a small number of chief executives and consultants but in fact organizational change is quite difficult and complicated. It may take such a long time for changing an organization and the first factor to be considered is employees in organizations. Their necessary skills and attitudes need to be improved before change so as to achieve preparedness which is an important thing making organizational change successful[9].

There are many methods in the process of organizational change but the methods widely accepted and used are Kurt Lewin's 3-stage model of change and John P. Kotter's 8-step change model. Both models have similarity and enhance each other. Differences can be seen in details of practicing[10] as follow: 1. Kurt Lewin's model involves 3 stages as unfreezing, changing, and refreezing. According to Lewin, the process of change entails creating the perception that a change is needed, the moving toward the new desired level of behavior and, finally, solidifying that new behavior as the norm. [11]

2. According to John P. Kotter, the 8-step change model involve create urgency, form a powerful coalition, create a vision for change, communicate the vision, remove obstacles, create short-term wins, build on the change, anchor the change in corporate culture.

\section{Management under technological change}

Management under technological change requires smart leaders. The era of change is full of internal and external organizational changes. Therefore, leaders need to develop themselves at all times to ensure their knowledge and skills can keep pace with the changes according to the theory of Bass \& Avolio[12]; idealized influence, inspirational motivation, intellectual stimulation, and individual consideration. Management shall follow the 3 strategies as[13]

1. Having the right person for the right job - Working in the new era requires a higher number of specialized employees. It can be seen that many organizations, from public and private sectors, have developed several projects to attract newly graduated people with knowledge and skills into their organizations so as to develop their potential and 
enable them to learn the actual working system for being executives of organizations accordingly; for example, Public Service Executive Development Program - PSED held by Office of the Public Sector Development Commission or Management Trainee Project of the Central Group, etc.

2. Employee retention strategy - To retain positive staff in organizations is challenge that organizations are facing. It is interesting that organizations with low employee turnover rates use which technique to retain employees with them. Mentioned about the world's most desirable workplace, it is "Google" company where around 50,000 employees are working. The company includes a mixture of people from different nationalities and cultures across the world. The important key that Google uses to retain its employees is not salary rates like many persons think about but an explicit organizational culture with good communication that each employee is treated equally. Workplace and environment support employees to exercise their creativity including career support and various activities.

3. Adoption of digital strategies to help increase organization efficiency

Adopting digital technology to organizations in an appropriate manner is as important as having potential employees. Nowadays, it is the era in which a large amount of information is circulated. That is big data consisting of extensive data sets like text, document, audio, image, song, video, etc. Organizations should figure out a method to manage such data to prepare for marketing and customer service strategies. Organizations must plan further how they can be able to keep pace with changes that are going to occur. The important thing that helps promote stability and sustainability of organizations is making understanding of organization environment including service users. The only factor that enables organizations to access needs and behaviors of customers is decoding "data". Making understanding of big data is the important key of the organizations of the future.

It can be concluded that management under technological change requires competent leaders who possess idealized influence, inspirational motivation, intellectual stimulation, and individual consideration by managing organizations in accordance with 3 strategies like having the right person for the right job, employee retention strategy, and adoption of digital strategies to help increase organization efficiency.

\section{Conclusion}

Leadership of organization administrators under the era of technological change includes policies for future, systematic methods to look for and predict changes, right methods to get familiar with internal and external organizational changes, policies on getting the right balance between changes and continuity as policies on creating new things in a systematic manner are under important roles as follow:

1. Getting to know changes. The world is in the era of technology and information. Knowledge is a key to gain competitive advantage.

2. Leaders need to make changes by specifying goals and methods to handle changes by means of strategic change planning before implementation.
3. Being change agents. Emphasis is placed on overall performance rather than individual performance in organizations so as to learn situations and crisis that organizations are facing.

4. Being thinkers and developers who can keep pace with global changes, have a broad vision in management and get ready to cope with changes without attachment to anything.

5. Democratic management style, listening to opinions of others, thinking together, working together, and joining to solve problems with personnel in organizations.

6. Being organizational coordinators to ensure smooth operations, focusing on working efficiency and coordinating outside organization to seek participative networks.

7. Compromise - Leaders shall make their attempt to avoid employee conflict in the workplace. Leaders must be a mediator in the compromise when problems arise.

8. Public relations - Leaders shall support everyone to prepare a performance report and the report shall be publicized to related persons and public.

9. Public welfare - Leaders must give assistance and care to coworkers as well as continuous development to ensure everyone has a chance of career advancement, forgiveness, warning, and fellowship.

\section{References}

[1] Pachsiry Chompukum, Organization and management, (Bangkok: McGraw Hill Publishing, 2009), pages 3-7.

[2] Bass, Full range leadership development: Manual for the Multifactor leadership Questionnaire. (Pale Alto, CA: Mind garden, 1997), p. 92.

[3] Sittichoke Waranusantikul, Social psychology: theories and applications, (Bangkok: SE-Education Public Company Limited, 2003), page 263

[4] Thanawat Tangsinsapsiri, Organizational behavior, (Bangkok: Thanatat Printing Co.,Ltd, 2007), page 219.

[5] Soitrakul (Tewyanon) Attamana, Organizational behavior: theories and applications, the 3rd edition, (Bangkok: Thammasat University Press, 2002), page 253.

[6] Rattikorn Jongwisarn, "Transformational leadership", Kasetsart Journal of Social Sciences,(2002):121.

[7] Bass, B.M., \& Avolio, B.J., Transformational leadership and Organizational Culture. New York: SUNY- Binghamton, 1993) pp. 112-113. 
[8] Manoon Tayananupat, Organizational change, [online], source: http://peoplevalue.co.th/346/ [6 February 2020].

[9] Jirapong Ruanggoon," Organizational change: concepts, process and the roles of human resources professional", Panyapiwat Journal Volume 5 (2013): 194-203.

[10] Pichapob Panpae, Leadership and change management, (the 2nd edition), (Bangkok: Chulalongkorn University Press, 2011), page 65.

[11] Bunga Posiw, Change management: the role of internal communication, [online], Source:

http://utcc2.utcc.ac.th/academicweek_ proceeding/2553/ huminities/bunga.pdf [February 2, 2020].

[12] Ibid, pp. 112-113.

[13] Nisachol Chatthong, "Context Thailand government to step into an innovation organization", Journal of Information, Vol.7, No.1 (2018): January-June: 31-32. 